\title{
Comparison of Evolutionary Computation and Empirical Penman-Monteith Equation for Daily and Monthly Reference Evapotranspiration Estimation in Tropical Region
}

\author{
Saiful Farhan M. Samsuri ${ }^{1 *}$, Robiah Ahmad ${ }^{2}$, Mohd Zakimi Zakaria ${ }^{3}$ \\ ${ }^{1}$ Department of Applied Mechanics \\ Universiti Teknologi Malaysia (UTM), Skudai Johor, 81310, MALAYSIA \\ ${ }^{2}$ UTM Razak School of Engineering \& Advanced Technology, \\ UTM International Campus, Kuala Lumpur, 54100, MALAYSIA \\ ${ }^{3}$ School of Manufacturing Engineering, \\ Universiti Malaysia Perlis (UniMAP), Arau Perlis, 02600, MALAYSIA \\ *Corresponding Author
}

DOI: https://doi.org/10.30880/ijie.2018.10.07.011

Received 20 August 2018; Accepted 19 November 2018; Available online 30 November 2018

\begin{abstract}
Evapotranspiration is the combination of evaporation and transpiration processes that give means the process of water loss to the atmosphere. Reference evapotranspiration (ETo) estimation is part of water cycle that importance for planning and management of irrigation purposes and water resource systems. Due to its importance, the accurate modeling of ETo is of vital importance to estimate crop water requirement and its availability. This research presents a system identification and differential evolution approach by using Differential Evolution and System Identification (DESI) and Modified Genetic Algorithm (MGA) approach for modeling daily and monthly ETo in peninsular of Malaysia. The data set comprising air temperature, humidity, wind speed, and solar radiation was utilized for estimating ETo using FAO56 Penman Monteith (PM) equation as the reference. The modeling results were analyzed and compared with the traditional Penman Monteith method. Based on the analyses, the approach used was found that the models of ETo is adequate and understandable, and suited to estimate the dynamics of the evapotranspiration process. The performance of the model is comparable with that of the PM method.
\end{abstract}

Keywords: Evapotranspiration; System Identification; Evolutionary Computation; Crop Water Estimation

\section{Introduction}

Reference evapotranspiration information or denoted as ETo was introduced by the United Nations Food and Agriculture Organization (FAO) as a methodology for calculating crop evapotranspiration [1] is widely used in irrigated plantation to calculate crop water requirements and plan the use of water resources efficiently. Estimation of crop evapotranspiration successfully used in water resources management, hydrological cycle, water quality prediction, and reservoir operation. Furthermore, accurate assessment of ETo is essential in estimation of water requirement, water resources planning and management, irrigation scheduling, water allocation and determination of the water budget.

Last previous decades there has been a widespread interest in the application of ETo. Since the PM method provides precise ETo values in various climate areas and has shown comparable and good performance [2],[3],[4] therefore it has been widely known as standard calculating ETo [5], [6]. The studies unveiled over evaporative processes, most models 
of evapotranspiration were reflecting some measure of climatological control. Evapotranspiration rate can then be obtained by multiplying the reference evapotranspiration by the crop coefficient. The PM method is shown to perform well for dense, shaded canopies areas and wet vegetated cover [7]. However, the PM equation requires for data applicability which are not readily available such as surface and aerodynamic resistance.

Due to the interdependence of the factors affecting the evapotranspiration, the study on the evaporative demand of the crop regardless of type, its stage development and its management is difficult. Traditionally, evaporation was measure of by lysimeter and pan-evaporimeter are subjected to a large set of assumption, labor-intensive, and may irrelevant for big-scale studies. 10 different methods used has been reviewed by Rana and Katerji [4] for measuring and estimating actual ETo at farm scale in Mediterranean region where each method possessed advantages and constraint. most frequent devices used to measure crop ETo are Class A Pan (CAP) and Piche Atmometers (ATM) [8] as well as lysimeter and Andersson evaporimeter (ANE). These methods were evaluated by [3] in Chile to measured crop ETo inside greenhouse climates and compared with empirical PM equations and FAO-Radiation equation with correlations values $R^{2}$ measured directly by lysimeter. ET also can be measured directly by experimental, e.g. lysimeters, eddy covariance systems, and Bowen ratio energy balance [9], [10], but these methods are complex, costly and not available in many regions [11], [12]. Therefore, development of mathematical models for ET estimation is highly requisite, which usually relies on reference ETo.

The complexity of evapotranspiration modeling has led researchers to test the utility of data-driven models using conceptual models and can be summarized and categorized into: (i) physically-based equations and (ii) empirical relationships (meteorological data). Li et al., (2010) predicted ETo with Pan Evaporation, $\mathrm{E}_{\mathrm{pan}}$ using calibrated $\mathrm{K}_{\mathrm{p}}$ and with 4-variable regression function method and the studies were conducted at six locations in northern China. Both methods gave good prediction. They concluded that $\mathrm{E}_{\mathrm{pan}}$ is simple, relatively accurate and requires minimal historic climatic data. Another example was by [14] using time series simulation model ARIMA. Due to the development of computing technologies, researchers have moved toward applying these in modeling ETo. Examples studies using artificial neural networks (ANNs) and neuro-fuzzy model i.e. by [15], [16] and [17] in conjunction with Hargreaves ETo equation. The Extreme Learning Machines (ELM) approach can be used to estimate the ETo using minimum weather data in their calculation [18]-[19] and using genetic algorithm by Guo et al.[20] and [21], as well as Kim et al.[15] and [22]. Another approach is using artificial intelligence (AI) modeling. This technique allows researchers to map the nonlinear relationship without the need explicitly specify the mathematical equation for the model. Since most approach is based on component-oriented and programming based, the ETo estimated with the modified PM equation can be accessed by the software i.e. [23] and they revealed the practicability of using these methods without necessity of complex equations in typical PM-ETo calculations.

The main objective of the present study is to estimate the ETo by using Differential Evolution and System Identification (DESI) and Modified Genetic Algorithm (MGA) approach. The DESI and MGA algorithm are proposed especially for modeling daily and monthly ETo in peninsular of Malaysia. A linear-in-the-parameter Finite Impulse Response (FIR) model was used as model representation. The equation FAO-56 PM has been used as the reference and the performance will be validated and compared with PM estimates. The paper is organized as follows. The next section presents PM empirical equation followed by description of datasets used in this study. Next, a model representation that used in the DESI algorithm and MGA is elaborated. The following section explains the DESI and MGA algorithm and model validation. Then, the ETo equation and data description are presented in the following section. After that section, the results and discussions of the study are presented. The final section provides the contribution of the study.

\section{Research Method}

\subsection{Penman-Monteith Reference Evapotranspiration Equation}

Numerous methods to estimate ETo have been developed and the FAO-56 PM equation that been proposed by FAO is recommended as a method for determining ETo. This method has been selected because it closely approximates grass ETo at the location evaluated, is physically based, and explicitly incorporates both physiological and aerodynamic parameters. Hence, the equation is proposed as the standard equation for estimating ETo and for evaluating other methods [24]. The FAO-56 PM equation proposed for $\mathrm{ET}_{\mathrm{O}}$ estimation [2] was written as:

$$
E T_{o}=\frac{0.484 \Delta\left(R_{n}-G\right)+\gamma\left(\frac{900}{T+273}\right) u_{2}\left(e_{s}-e_{a}\right)}{\Delta+\gamma\left(1+0.34 u_{2}\right)}
$$

where ETo is the standardized reference ET, $\mathrm{mm} \mathrm{d}^{-1}$ for daily time steps, or $\mathrm{mm} \mathrm{m}^{-1}$ for monthly; $R_{n}$ is the calculated net

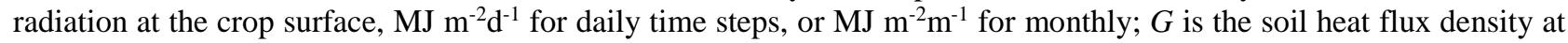
the soil surface, $\mathrm{MJ} \mathrm{m}^{-2} \mathrm{~d}^{-1}$ for daily time steps, or $\mathrm{MJ} \mathrm{m}^{-2} \mathrm{~m}^{-1}$ for monthly; $T$ is the mean daily or monthly air temperature, ${ }^{\circ} \mathrm{C} ; u_{2}$ is the mean daily or monthly wind speed, $\mathrm{ms}^{-1} ; e_{s}$ is the saturation vapor pressure, $\Delta$ the slope of the vapour pressure curve $\left(\mathrm{kPa}^{\circ} \mathrm{C}^{-1}\right)$, Net radiation can be estimated from Eqns. (21) to (25), (28)-(33), (38)-(40) in [25]. 


\subsection{Data Description}

The daily data recorded at two meteorological stations (Senai and KLIA) managed by the Malaysian Meteorological Department (MMD) are used to evaluate the performance of the weather data estimation from weather forecasts using the PM method. The respective locations are described as at coordinate (latitude $2.017 \mathrm{~N}$, longitude of $103.19^{\circ} \mathrm{E}$ elevation of 88.1) for Senai and (latitude $2.733^{\circ} \mathrm{N}$, longitude $101.7^{\circ} \mathrm{E}$, elevation 16.3) for KLIA as show in Fig. 1. For estimating ETo, the data was logged and recorded for a month period August 2011 and this period was selected including temperatures, wind speed, relative humidity, and solar radiation. The needs for checking the quality of weather data and approaches for their correction also discussed by Allen et al.[11].

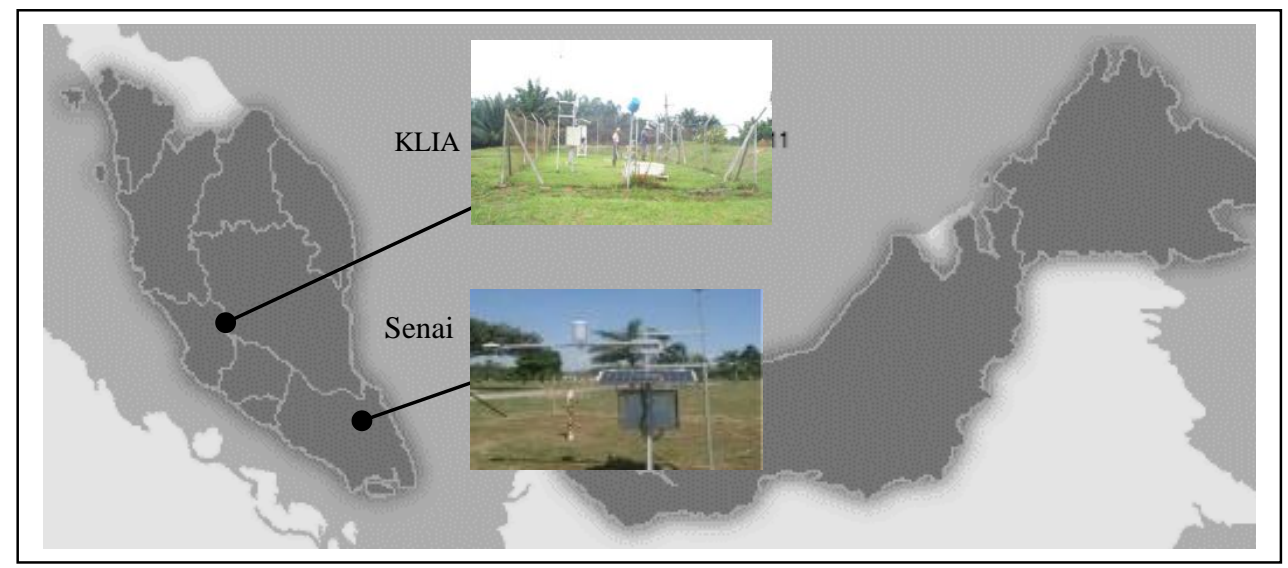

Fig.1 - Location of the weather stations used in this study.
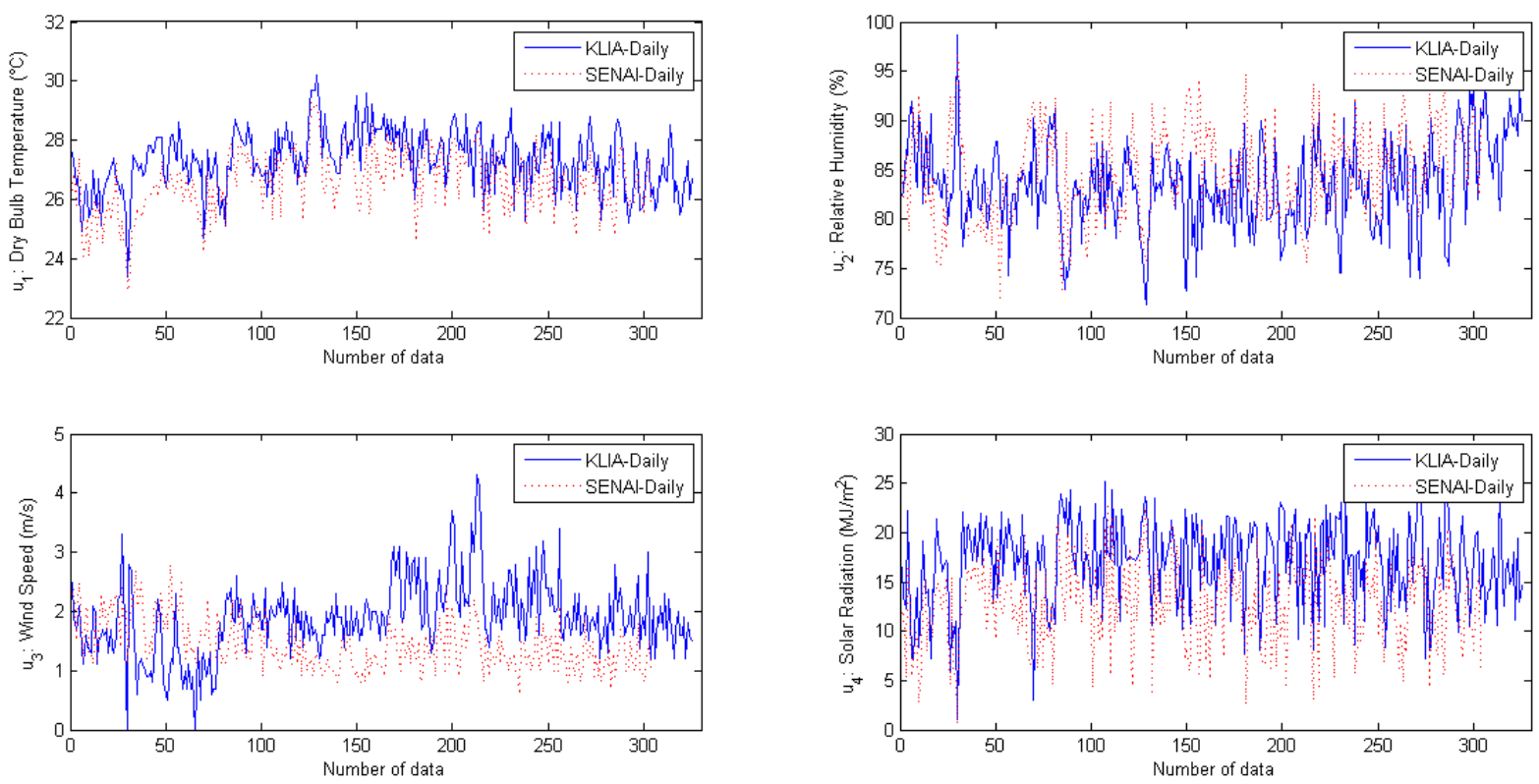

Fig 2 - The inputs of KLIA and Senai for daily dataset 


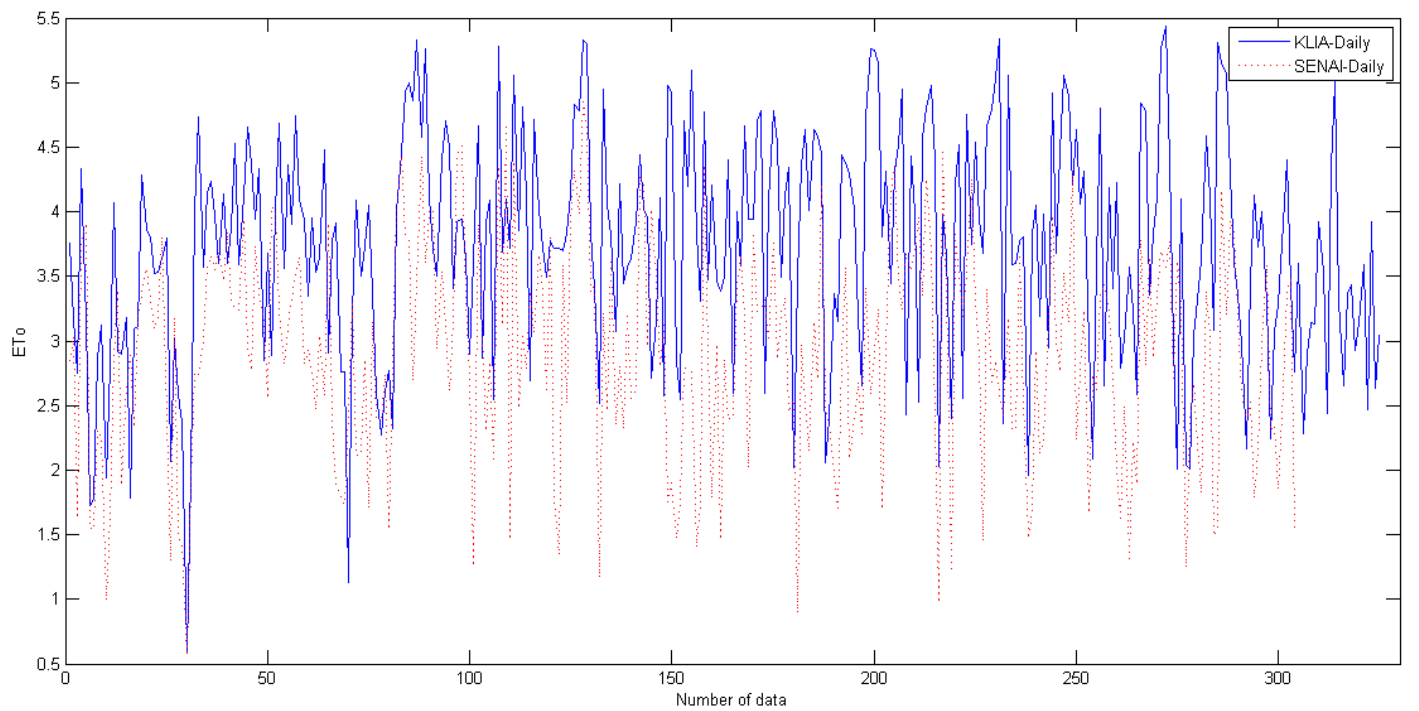

Fig 3 - The ETo values of KLIA and Senai for daily dataset
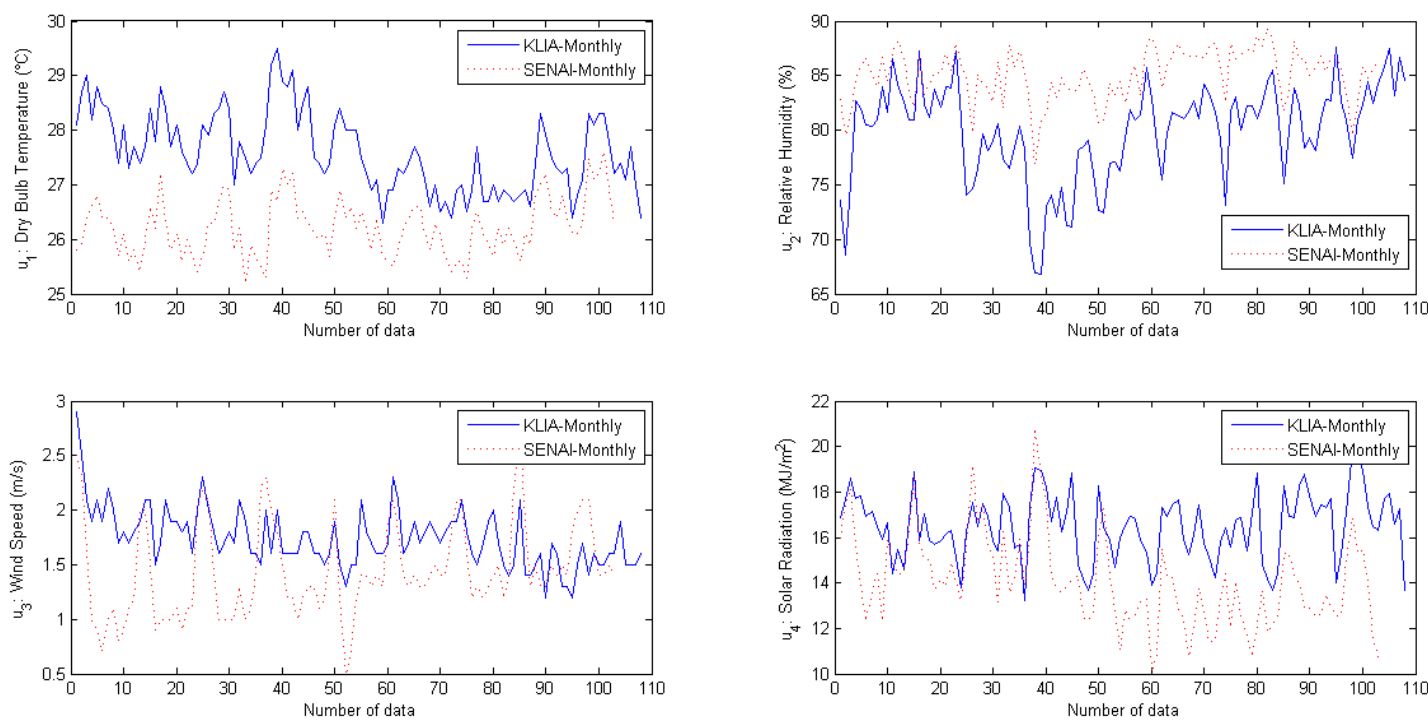

Fig 4 - The inputs of KLIA and Senai for monthly dataset

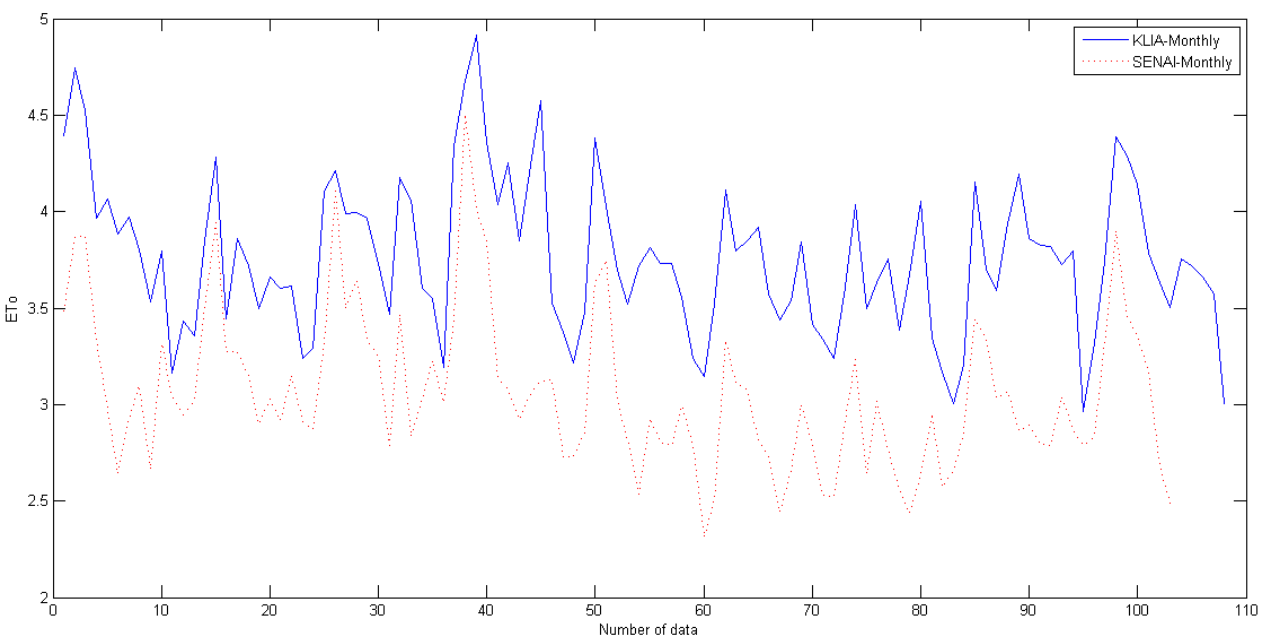

Fig 5 - The ETo values of KLIA and Senai for monthly dataset 


\section{Modeling and Algorithms}

In system identification, a suitable model is needed in representing a dynamic system. This section will elaborate a model to be used in estimating ETo values and algorithms implemented in the modeling daily and monthly ETo for the selected locations.

\subsection{Model description}

The model representation gives the information and characteristics of that system to be modeled. Example of model types that usually used in the modeling dynamic systems are: AutoRegressive with eXegeneous inputs (ARX) for modeling linear systems, while for nonlinear systems are Nonlinear ARX (NARX), i.e. state space model, neural network model, and fuzzy model. Examples of ARX and NARX models used for various applications are such as in [26],[27],[28],[29]. In ARX model, basic relationship between the input and output in linear difference equation described as:

$$
y(t)=-a_{1} y(t-1)-\cdots-a_{n_{y}} y\left(t-n_{y}\right)+b_{1} u(t-1)+\cdots+b\left(n_{u}\right) u\left(t-n_{u}\right)+e(t)
$$

where $a_{1} \ldots a_{n y}$ and $b_{1} \ldots b_{n u}$ is coefficient of output and input models and $e(t)$ represents white noise. Eq. (2) is used in modeling linear discrete-time of single variable system while the equation for multivariable system is:

$$
y(t)=-a_{1} y_{1}(t-1)-\cdots-a_{n_{y}} y_{i}\left(t-n_{y}\right)+b_{1} u_{1}(t-1)+\cdots+b_{n_{u}} u_{j}\left(t-n_{u}\right)+e(t)
$$

where $i$ and $j$ is number of input and output respectively. While study is only considered input variables where $n_{y}$ is zero, or called Multi Input Single Output (MISO) system and can be represented by:

$$
y(t)=C+b_{1} u_{1}(t)+b_{2} u_{1}(t-1)+\cdots+b_{n_{u}} u_{j}\left(t-n_{u}\right)+e(t)
$$

where $C$ is constant that was added for reducing the effect of the disturbance. According to Ljung [30], Eq. (4) is called Finite Impulse Response (FIR) model was commonly used in signal-processing applications [31]. Besides, it has been widely used for it guaranteed stability and simplicity. The coefficients of input models are estimated using Least Square Estimation (LSE) as shown in Eq. (5):

$$
\theta_{k}=\left[U_{k}^{T} U_{k}\right]^{-1} U_{k}^{T} Y
$$

where $U$ and $Y$ are vectors of input and output data respectively, $\theta$ is estimated parameter, and $k$ is number of inputs [32].

In this study, the ETo is predicted using Eq. (1) as the model representative by considering ETo as the output $y(t)$ at the time $t$, while $u_{1}, u_{2}, u_{3}$, and $u_{4}$ represent air temperature $\left({ }^{\circ} \mathrm{C}\right)$, relative humidity $(\%)$, wind speed $(\mathrm{m} / \mathrm{s})$, and solar radiation $\left(\mathrm{MJ} / \mathrm{m}^{2}\right)$ respectively as the inputs. The description of data used is elaborated in next section. The algorithms used in this study are modified Genetic Algorithm (MGA) and a combination of Differential Evolution and System Identification (DESI). These algorithms are elaborated in the next sub-sections.

\subsection{Modified Genetic Algorithm (MGA)}

Genetic algorithm (GA), is mathematical models of natural genetics were developed by [33], is a stochastic optimization technique where the power of nature to develop, destruct, improve and annihilate life is abstracted and used to solve complex optimization problems. The implementation of algorithm can be summarized as follow [34] and shown as Fig. 6(a) below. The optimal FIR model is selected by applying the MGA for estimating daily and monthly ETo values. To get the maximum number of terms, $M$ the model parameters must be set (i.e. output lag, $n_{y}$ and input lag, $n_{u}$ ) for full polynomial model representation

The evolution initiate with $(t=1)$ till the maximum number of generation, then the coefficients of the terms are estimated using Eq. (5). The predicted system output, $\hat{y}(t)$ is calculated using the collected data pairs. To calculate the objective function, $O F$ using Eq. (6), The fitness of each chromosome in the population is calculated before iteration stops when it reached maximum generation.

$$
O F=\sum_{i}^{N}(y(t)-\hat{y}(t))+\log C_{k}
$$

where $y($.$) and \hat{y}($.$) is actual and predicted output respectively, \log C_{k}$ and $N$ is penalty added and number of data, respectively.

\subsection{Differential Evolution and System Identification (DESI)}

The proposed algorithm called DESI algorithm is a combination of differential evolution and system identification. The proposed algorithm is formulated for estimating ETo values. There are two major parts of the proposed algorithm: the first one is partly based on differential algorithm, the second one is to generate a model for estimating ETo through system identification process. Details implementation of DESI algorithm in modeling daily and monthly ETo, are as follows shown as Fig. 6(b) below. To define objective function, the selected term of the identified model is estimated 
using LSE algorithm. Thus, the OF can be use and calculated same as Eq. (6), where the values of $\hat{y}(t)$ is used, $y(t)$ and $C_{k}$ are actual output and the number of insignificant terms respectively.

Create parent population, $P_{t}$ and offspring population, $Q_{t}$, with size of population size, NP. After the new vectors are produced in the population, the OF for the new vectors are defined for both $P_{t}$ and $\mathrm{Q}_{t}$. Create new generation of population, $P_{t+1}$ with size NP and select final population of $P_{t+1}$ by using greedy selection proposed by [35].

\subsection{Model Validation}

Statistical analysis is used to validate and evaluate the performance the predicted outputs of the models with the actual values of the outputs obtained experimentally. The strength of the relationship between the predicted and experimental outputs is indicate using coefficient of determination $\left(R^{2}\right)$ as given by [36];

where $S_{x y}, S_{x x}$ and $S_{y y}$ are respectively given by

$$
\hat{y}_{O S A}(t)=\widehat{F}_{l}\left[y(t-1), \ldots, y\left(t-n_{y}\right), u_{1}(t-1), \ldots, u_{j}\left(t-n_{u}\right)\right]
$$

$$
\begin{aligned}
S_{x y} & =\sum_{i=1}^{n} x_{i} y_{i}-\frac{\left(\sum_{i=1}^{n} x_{i}\right)\left(\sum_{i=1}^{n} y_{i}\right)}{n} \\
S_{x x} & =\sum_{i=1}^{n} x_{i}{ }^{2}-\frac{\left(\sum_{i=1}^{n} x_{i}\right)^{2}}{n} \\
S_{y y} & =\sum_{i=1}^{n} y_{i}{ }^{2}-\frac{\left(\sum_{i=1}^{n} y_{i}\right)^{2}}{n}
\end{aligned}
$$

in which $n$ is the total number of data in the particular data set.
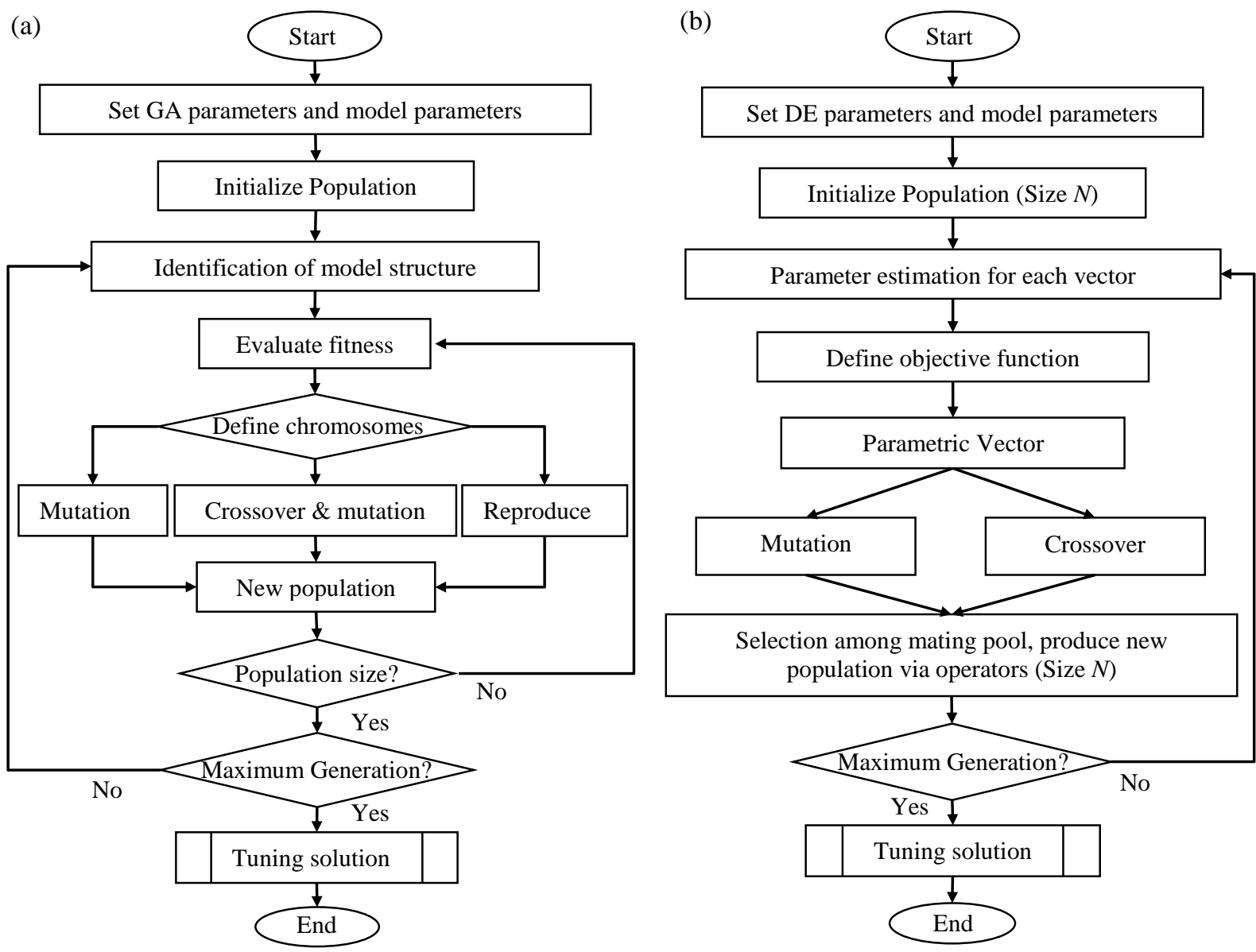

Fig. 6 - (a) MGA flow chart; (b) DESI flow chart.

Furthermore, mean square error (MSE), root mean square error (RMSE) and sum square error (SSE) also measured to validate the models. The accuracy of the FIR model prediction can be measured and compared the predicted output with the previous input and output data using a one-step ahead prediction (OSA). 


\section{Result and Discussion}

Four models are used in investigating the performance of the algorithms to model daily and monthly ETo as listed in Table 1. These models are developed based on FIR model as described in Eq. (3). The models with linear in their parameters and structures are considered. The models have different number of terms $M$ which increased as the input and output lags increased.

Table 1 - Model description whereas $n_{u}$ and $n_{y}$ are input and output lags respectively.

\begin{tabular}{lccc}
\hline Model & $\mathbf{n}_{\mathbf{u}}$ & $\mathbf{n}_{\mathbf{y}}$ & Number of terms \\
\hline Model 1 & 2 & 2 & 13 \\
Model 2 & 3 & 3 & 17 \\
Model 3 & 4 & 4 & 21 \\
Model 4 & 5 & 5 & 25 \\
\hline
\end{tabular}

\subsection{Estimating ETo using MGA}

Tables 2-3 represent the results for daily and monthly dataset using MGA algorithm. As the model size gets larger, the statistics error gets lower in values. Although models with lower number of terms, they are capable in capturing the daily and monthly ETo values in both stations. The values for SSEv and RMSEv in the tables showed that Model 1 has shown the lowest value. Therefore, it can be concluded that Model 1 outperformed the other models in terms of model size and error statistics in both training and validation periods.

Table 2 - Results of applied MGA models in KLIA and Senai for Daily dataset

\begin{tabular}{ccccccc}
\hline \multirow{6}{*}{ KLIA } & Model & MSEt $\left(\times \mathbf{1 0}^{-\mathbf{3}}\right)$ & SSEv & $\mathbf{R}^{2}$ & RMSEv & Model size \\
& Model 1 & 22.5 & 8.230 & 0.9607 & 0.1601 & 3 \\
& Model 2 & 27.9 & 10.830 & 0.9512 & 0.1840 & 3 \\
& Model 3 & 3.64 & 1.460 & 0.9937 & 0.0676 & 7 \\
& Model 4 & 5.30 & 2.891 & 0.9874 & 0.0954 & 7 \\
\hline \multirow{3}{*}{ SENAI } & Model 1 & 3.83 & 0.935 & 0.9955 & 0.0558 & 5 \\
& Model 2 & 26.8 & 5.488 & 0.9724 & 0.1355 & 3 \\
& Model 3 & 39.8 & 7.707 & 0.9654 & 0.1608 & 5 \\
& Model 4 & 6.91 & 2.600 & 0.9872 & 0.0936 & 8 \\
\hline
\end{tabular}

Table 3 - Results of applied MGA models in KLIA and Senai for Monthly dataset

\begin{tabular}{ccccccc}
\hline \multirow{6}{*}{ KLIA } & Model & MSEt $\left(\times \mathbf{1 0}^{-3}\right)$ & SSEv & $\mathbf{R}^{2}$ & RMSEv & Model size \\
\hline \multirow{6}{*}{ SENAI } & Model 1 & 3.17 & 0.328 & 0.9781 & 0.0561 & 4 \\
& Model 2 & 18.6 & 4.326 & 0.7404 & 0.2049 & 4 \\
& Model 3 & 3.21 & 0.426 & 0.9723 & 0.0647 & 7 \\
& Model 4 & 1.94 & 0.321 & 0.9791 & 0.0564 & 7 \\
\hline & Model 1 & 0.79 & 0.205 & 0.9879 & 0.0455 & 4 \\
& Model 2 & 3.99 & 0.443 & 0.9720 & 0.0673 & 5 \\
& Model 3 & 2.44 & 0.347 & 0.9794 & 0.0598 & 5 \\
\hline
\end{tabular}

\subsection{Estimating ETo using DESI}

The results for estimating daily and monthly ETo using DESI algorithm are shown in Tables 4-5. The values for statistical errors for all different models are significantly consistent as shown in Tables 4 . The results indicate that DESI algorithm has shown consistency in producing a good predictive model to estimate ETo values. DESI algorithm needs to justify one type of model while executing. even Model 3 show slightly better result in Table 5, nevertheless in overall the Model 1 is chosen as a good model to be used in modeling ETo for most cases (daily and monthly) and places (KLIA and Senai) 
Table 4 - Statistical results for applied model KLIA and Senai Daily dataset

\begin{tabular}{ccccccc}
\hline \multirow{6}{*}{ KLIA } & Model & MSEt $\left(\times \mathbf{1 0}^{-3}\right)$ & SSEv & $\mathbf{R}^{\mathbf{2}}$ & RMSEv & Model size \\
\hline \multirow{6}{*}{ SENAI } & Model 1 & 8.37 & 2.608 & 0.9885 & 0.0901 & 3 \\
& Model 2 & 8.46 & 2.608 & 0.9885 & 0.0903 & 3 \\
& Model 3 & 8.54 & 2.596 & 0.9885 & 0.0902 & 3 \\
& Model 4 & 19.4 & 9.157 & 0.9642 & 0.1697 & 2 \\
\hline \multirow{6}{*}{ Model 1 } & 7.14 & 1.145 & 0.9944 & 0.0618 & 3 \\
& Model 2 & 7.20 & 1.145 & 0.9944 & 0.0619 & 3 \\
& Model 3 & 7.27 & 1.144 & 0.9944 & 0.0620 & 3 \\
\hline
\end{tabular}

Table 5 - Statistical results for applied models KLIA and Senai Monthly dataset

\begin{tabular}{ccccccc}
\hline \multirow{6}{*}{ KLIA } & Model & MSEt $\left(\times \mathbf{1 0}^{-3}\right)$ & SSEv & $\mathbf{R}^{\mathbf{2}}$ & RMSEv & Model size \\
& Model 1 & 2.81 & 0.3968 & 0.9751 & 0.0618 & 3 \\
& Model 2 & 2.72 & 0.3836 & 0.9750 & 0.0610 & 3 \\
& Model 3 & 2.77 & 0.3836 & 0.9749 & 0.0613 & 3 \\
& Model 4 & 2.83 & 0.3881 & 0.9745 & 0.0620 & 3 \\
\hline \multirow{3}{*}{ SENAI } & Model 1 & 2.17 & 0.3197 & 0.9815 & 0.0568 & 3 \\
& Model 2 & 1.02 & 0.2839 & 0.9830 & 0.0538 & 3 \\
& Model 3 & 4.97 & 0.6053 & 0.9609 & 0.0790 & 3 \\
& Model 4 & 5.42 & 0.6062 & 0.9635 & 0.0795 & 3 \\
\hline
\end{tabular}

\subsection{Comparison and evaluation of models using PM, MGA and DESI}

Daily and monthly data for two locations were used for the comparison and evaluation of MGA and DESI ETo models with PM ETo values. The summarized values are given in Table 6. The results indicate that MGA ETo model outperforms DESI for monthly dataset with lower values of error statistics. Meanwhile, DESI ETo model performs significantly better than MGA for daily dataset. Comparing inputs required for different models in estimating ETo, DESI ETo models show advantage with fewer input requirements.

Table 6 - Comparison results for all datasets

\begin{tabular}{|c|c|c|c|c|c|}
\hline Datasets & Model & Inputs & $\operatorname{MSE}_{t}\left(\times \mathbf{1 0}^{-3}\right)$ & $\mathbf{R}^{2}$ & $\mathbf{R M S E}_{\mathbf{v}}$ \\
\hline \multirow{3}{*}{$\begin{array}{l}\text { KLIA- } \\
\text { Daily }\end{array}$} & $\begin{array}{l}\text { Penman- } \\
\text { Monteith }\end{array}$ & $\begin{array}{l}\text { Temperature, relative humidity, wind } \\
\text { speed, solar radiation }\end{array}$ & - & - & - \\
\hline & MGA & $\begin{array}{l}\text { Temperature, relative humidity, wind } \\
\text { speed, solar radiation }\end{array}$ & 8.93 & 0.9815 & 0.1157 \\
\hline & DESI & Relative humidity, solar radiation & 8.37 & 0.9885 & 0.0901 \\
\hline \multirow{3}{*}{$\begin{array}{l}\text { Senai- } \\
\text { Daily }\end{array}$} & $\begin{array}{l}\text { Penman- } \\
\text { Monteith }\end{array}$ & $\begin{array}{l}\text { Temperature, relative humidity, wind } \\
\text { speed, solar radiation }\end{array}$ & - & - & - \\
\hline & MGA & $\begin{array}{l}\text { Temperature, relative humidity, solar } \\
\text { radiation }\end{array}$ & 8.37 & 0.9848 & 0.1038 \\
\hline & DESI & Relative humidity, solar radiation & 7.14 & 0.9944 & 0.0618 \\
\hline \multirow{3}{*}{$\begin{array}{l}\text { KLIA- } \\
\text { Monthly }\end{array}$} & $\begin{array}{l}\text { Penman- } \\
\text { Monteith }\end{array}$ & $\begin{array}{l}\text { Temperature, relative humidity, wind } \\
\text { speed, solar radiation }\end{array}$ & - & - & - \\
\hline & MGA & Relative humidity, solar radiation & 8.41 & 0.8704 & 0.1492 \\
\hline & DESI & Relative humidity, solar radiation & 14.8 & 0.8426 & 0.1713 \\
\hline \multirow{3}{*}{$\begin{array}{l}\text { Senai- } \\
\text { Monthly }\end{array}$} & $\begin{array}{l}\text { Penman- } \\
\text { Monteith }\end{array}$ & $\begin{array}{l}\text { Temperature, relative humidity, wind } \\
\text { speed, solar radiation }\end{array}$ & - & - & - \\
\hline & MGA & $\begin{array}{c}\text { Temperature, relative humidity, solar } \\
\text { radiation }\end{array}$ & 3.46 & 0.9727 & 0.0685 \\
\hline & DESI & Solar radiation & 5.44 & 0.9595 & 0.0861 \\
\hline
\end{tabular}


The mathematical expressions of ETo models for all dataset are listed in Table 7. Results from the table show that DESI ETo model produced a compact model with good predictive accuracy than MGA ETo model. The mathematical equations at daily dataset for DESI algorithm are shown almost the same in term of coefficients and parameters. The ETo models produced by both algorithms at all dataset, it can be seen a dominant climatic variable which is solar radiation, $U_{4}$, is existed. This is significantly showed at Senai-Monthly dataset where only one parameter existed in the model produced by DESI algorithm.

Table 8 displays the DESI and MGA ETo values versus PM ETo values for all dataset at KLIA and Senai stations. As can be seen from the scatterplots and fit line equations in Table 7, DESI models perform better than MGA models at daily dataset. Meanwhile, at monthly dataset, MGA models show slightly better than DESI models in term of $R^{2}$ values. However, DESI models have more scattered in estimating the ETo values than those of the MGA models to confirm the statistic errors in Table 8.

Figures 7-10 compares the ETo models using MGA and DESI algorithms with Penman-Monteith ETo for both daily and monthly datasets. The proposed algorithm MGA and DESI indicate that the estimation of ETo values can be achieved. The trend for ETo models using daily data sets are closely related to PM ETo as shown in Figures 7 and 8 . A reason behind this may be the daily dataset used are more accurate and reliable compared with monthly dataset. As can be seen in Figures 9 and 10, there are shown slightly difference in term of estimating monthly ETo values with the reference values. However, it is not very significant, with the trend of estimating ETo values are the same.

Table 7 - Mathematical expressions of ETo models for all dataset

\begin{tabular}{ccl}
\hline & \multicolumn{1}{c}{ Dataset } & \multicolumn{1}{c}{ Mathematical equation } \\
\hline \multirow{3}{*}{ MGA } & KLIA-Daily & ETo $(\mathrm{t})=8.47 \mathrm{E}-2 \mathrm{u}_{1}(\mathrm{t}-2)-2.10 \mathrm{E}-2 \mathrm{u}_{2}(\mathrm{t})+1.52 \mathrm{E}-1 \mathrm{u}_{3}(\mathrm{t})+1.24 \mathrm{E}-2 \mathrm{u}_{3}(\mathrm{t}-2)+1.71 \mathrm{E}-1 \mathrm{u}_{4}(\mathrm{t})$ \\
& Senai-Daily & $\mathrm{ETo}(\mathrm{t})=1.33 \mathrm{E}-1 \mathrm{u}_{1}(\mathrm{t})-2.86 \mathrm{E}-2 \mathrm{u}_{2}(\mathrm{t})+1.52 \mathrm{E}-1 \mathrm{u}_{4}(\mathrm{t})-2.95 \mathrm{E}-3 \mathrm{u}_{4}(\mathrm{t}-2)$ \\
\cline { 2 - 3 } & KLIA-Monthly & ETo $(\mathrm{t})=-3.23 \mathrm{E}-2 \mathrm{u}_{2}(\mathrm{t})+1.87 \mathrm{E}-2 \mathrm{u}_{2}(\mathrm{t}-2)+2.46 \mathrm{E}-1 \mathrm{u}_{4}(\mathrm{t})+5.32 \mathrm{E}-2 \mathrm{u}_{4}(\mathrm{t}-2)$ \\
& Senai-Monthly & ETo $(\mathrm{t})=7.16 \mathrm{E}-2 \mathrm{u}_{1}(\mathrm{t})-1.58 \mathrm{E}-2 \mathrm{u}_{2}(\mathrm{t}-2)+2.03 \mathrm{E}-1 \mathrm{u}_{4}(\mathrm{t})-2.50 \mathrm{E}-2 \mathrm{u}_{4}(\mathrm{t}-2)$ \\
\hline \multirow{3}{*}{ DESI } & KLIA-Daily & ETo $(\mathrm{t})=4.92-4.74 \mathrm{E}-2 \mathrm{u} 2(\mathrm{t})+1.59 \mathrm{E}-1 \mathrm{u}_{4}(\mathrm{t})$ \\
& Senai-Daily & ETo $(\mathrm{t})=4.93-4.72 \mathrm{E}-2 \mathrm{u} 2(\mathrm{t})+1.55 \mathrm{E}-1 \mathrm{u}_{4}(\mathrm{t})$ \\
\cline { 2 - 3 } & KLIA-Monthly & ETo $(\mathrm{t})=-9.92 \mathrm{E}-3 \mathrm{u}_{2}(\mathrm{t})+2.81 \mathrm{E}-1 \mathrm{u}_{4}(\mathrm{t})$ \\
& Senai-Monthly & ETo $(\mathrm{t})=2.14 \mathrm{E}-1 \mathrm{u}_{4}(\mathrm{t})$ \\
\hline
\end{tabular}

*E describes as exponential or usually using $\left(\times 10^{-\mathrm{n}}\right)$.

Table. 8 - Scatterplots of the DESI and MGA models during the validation period.

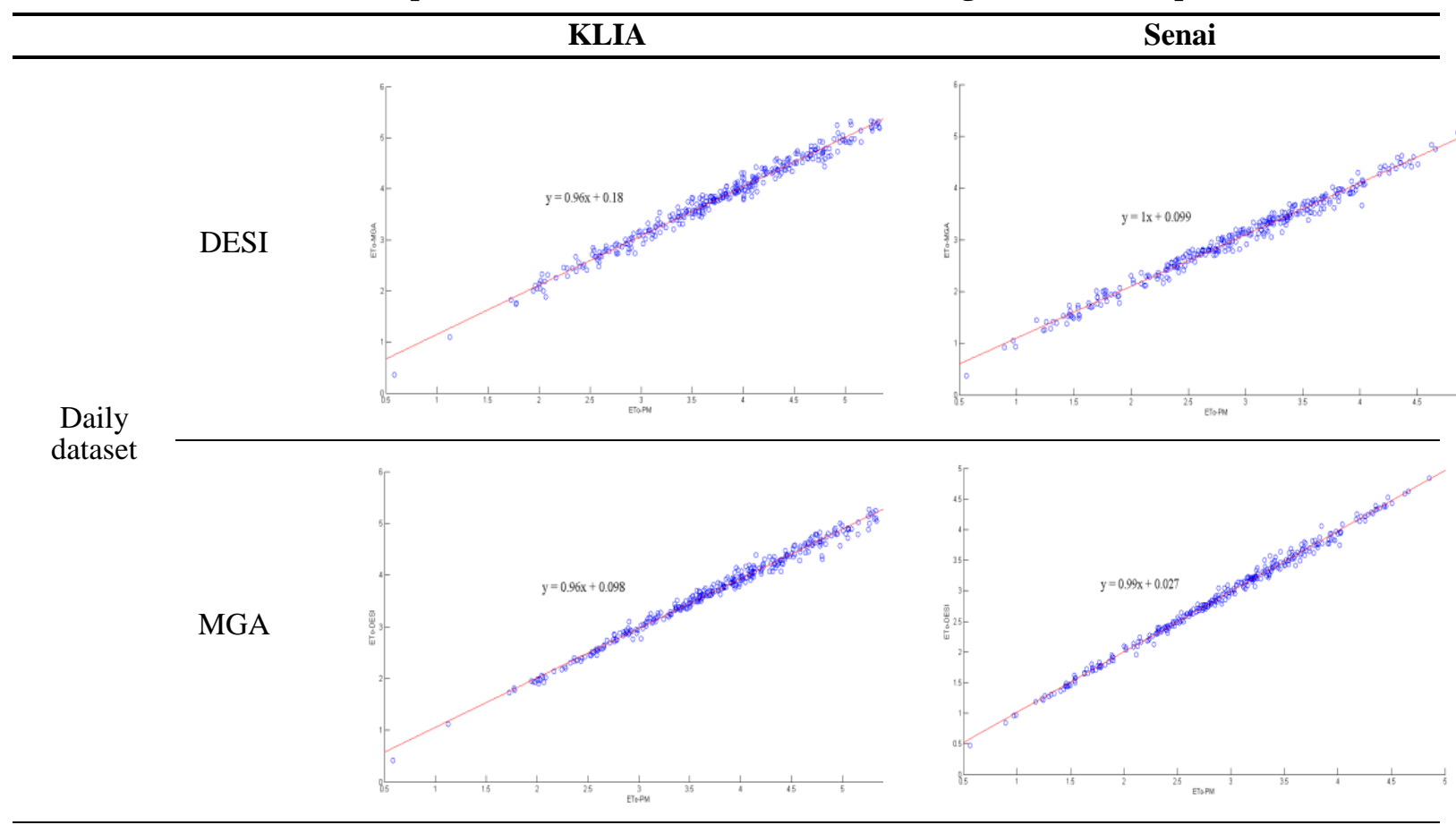



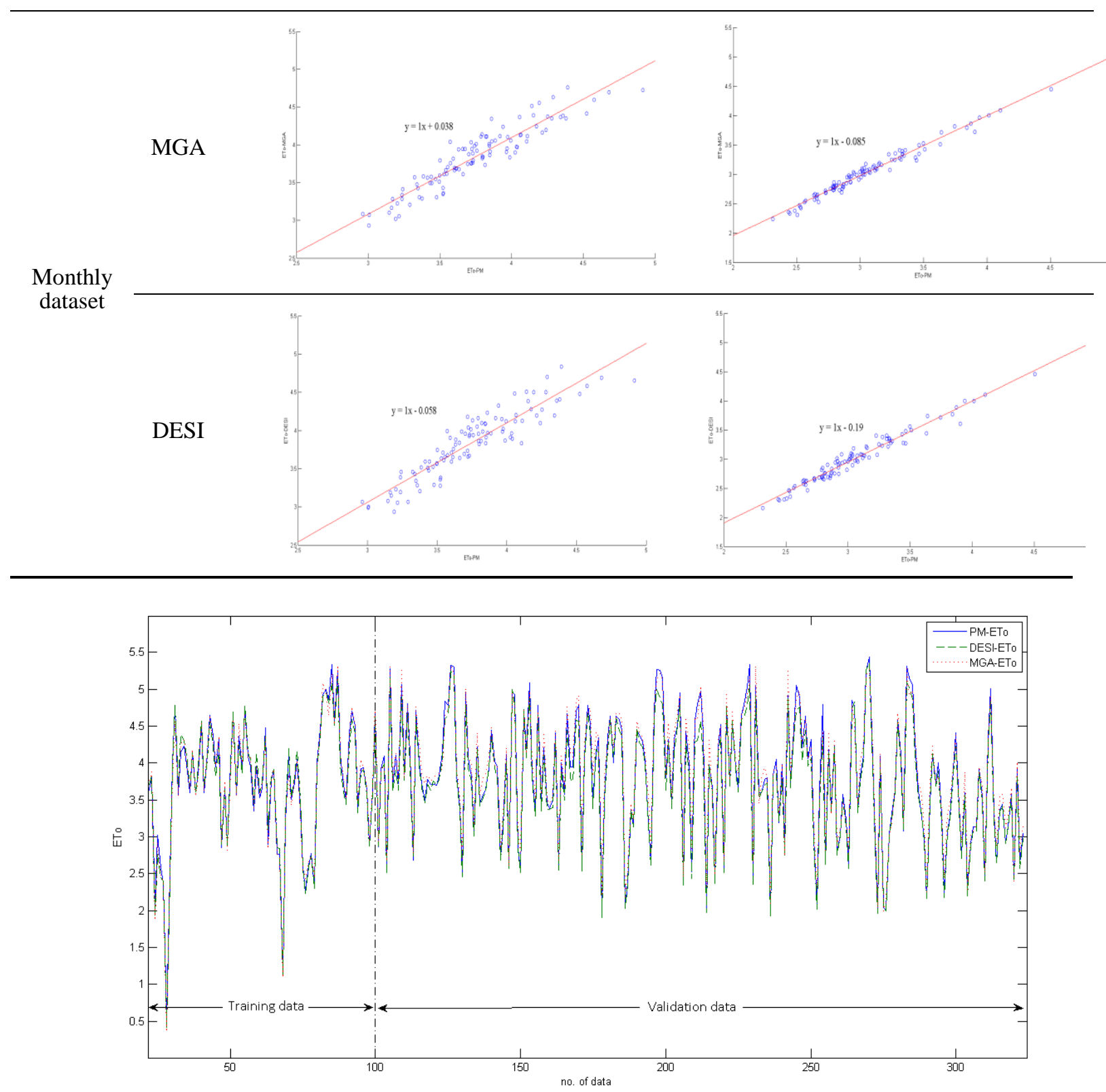

Fig 7 - Superimposed ETo values between PM, MGA, and DESI for KLIA-Daily dataset

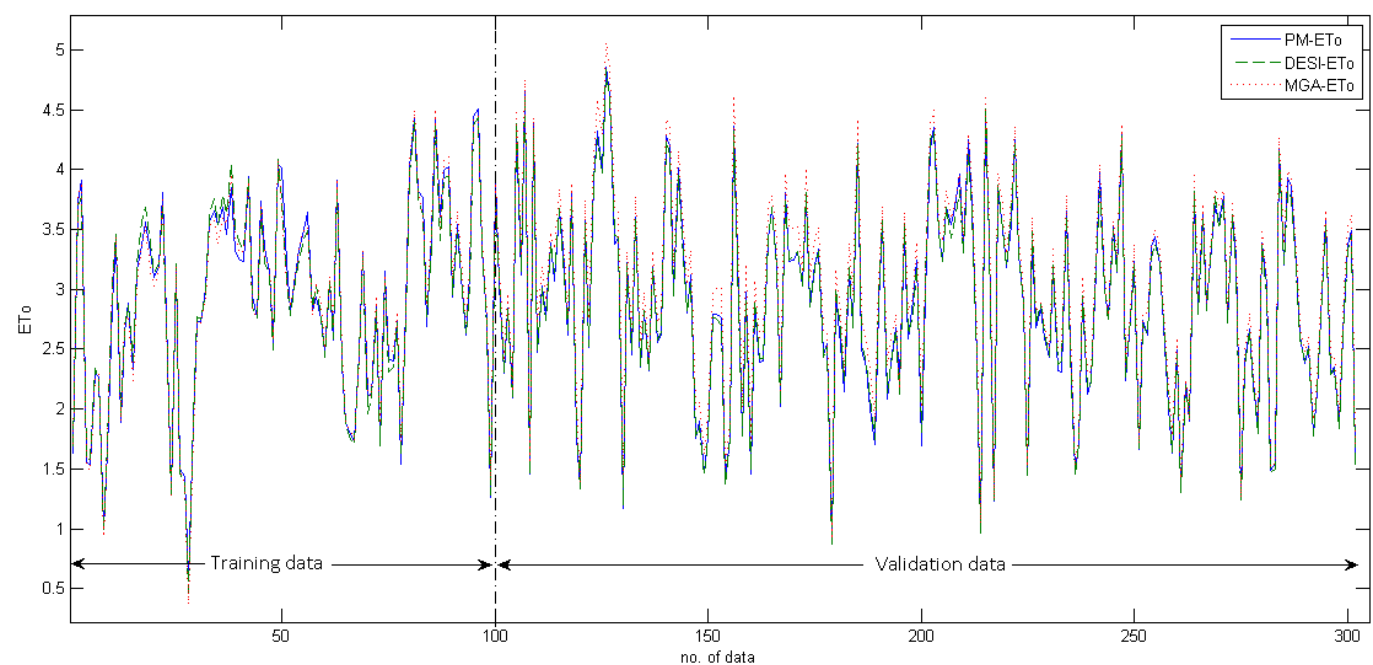

Fig 8 - Superimposed ETo values between PM, MGA, and DESI for Senai-Daily dataset 


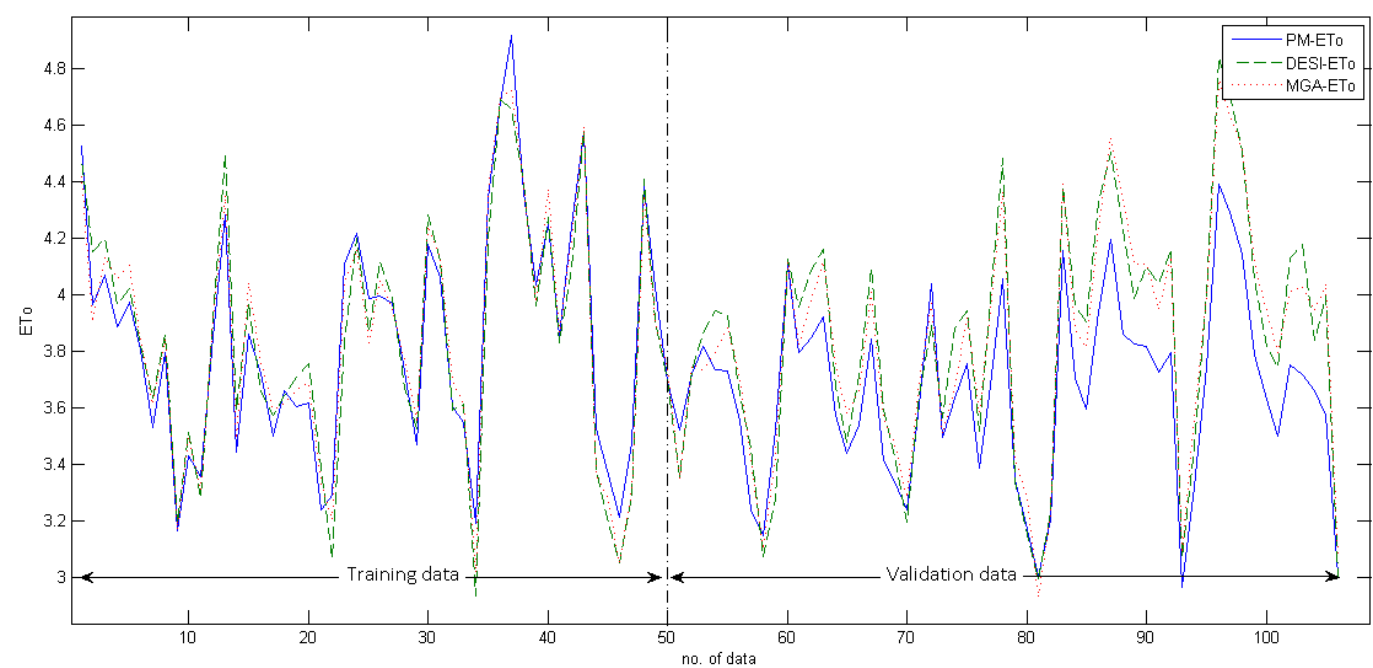

Fig 9 - Superimposed ETo values between PM, MGA, and DESI for KLIA-Monthly dataset

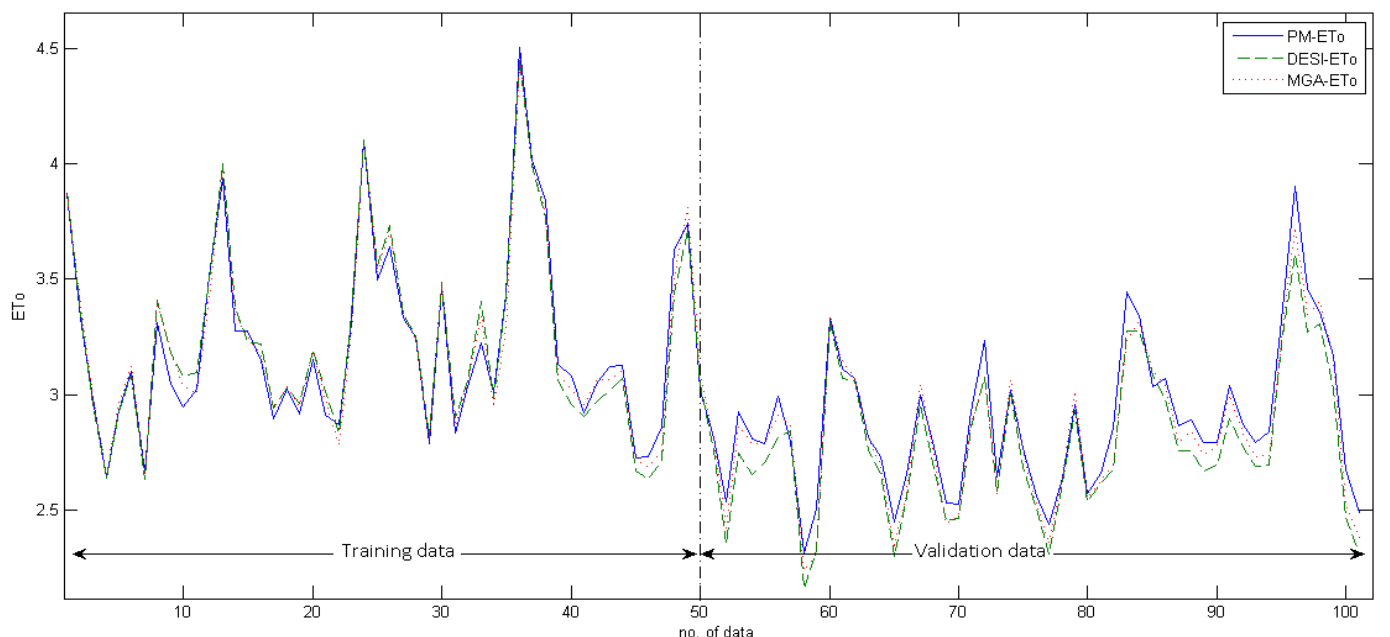

Fig 10 - Superimposed ETo values between PM, MGA, and DESI for Senai-Monthly dataset

\section{Conclusion}

In this study, the input-output data collected from the Reference Evapotranspiration or called ETo system was considered. The DESI algorithm produces good predictions of daily and MGA for monthly ETo in middle and southern peninsular of Malaysia. Comparison between the obtained MGA, DESI and the reference ETo-PM is comparable and showed almost identical. The results are able to imply the interrelations of four measurement inputs namely air temperature, relative humidity, wind speed, and solar radiation for estimating the ETo. From the MGA and DESI models, the dominant parameters are solar radiation. Thus, the estimation of ETo can be done with only these dominant parameters due to the absence of other parameters. As a conclusion of the results presented in this study, the MGA and DESI algorithm can be used in estimating daily and monthly ETo. This study shows that the proposed algorithm can be applied as an alternative algorithm to model the dynamic behavior of any process systems. For further studies, the different regions in Malaysia with the establishment of reliable climatic database system are investigated.

\section{References}

[1] J. Doorenbos and W. O. Pruitt, "Crop water requirements. FAO irrigation and drainage paper 24,” L. Water Dev. Div. FAO, Rome, vol. 24, p. 144, 1977.

[2] R. G. Allen, L. S. Pereira, D. Raes, and M. Smith, "Crop evapotranspiration: Guidelines for computing crop water requirements," in $F A O, 1998$, p. 300.

[3] M. Casanova, I. Messing, A. Joel, and A. Canete, "Methods to Estimate Lettuce Evapotranspiration in Greenhouse Conditions in the Central Zone of Chile,” Chil. J. Agric. Res., vol. 69, no. 1, pp. 60-70, 2009. 
[4] G. Rana and N. Katerji, "Measurement and estimation of actual evapotranspiration in the field under Mediterranean climate: A review,” in European Journal of Agronomy, 2000, vol. 13, no. 2-3, pp. $125-153$.

[5] M. Garcia, D. Raes, R. Allen, and C. Herbas, "Dynamics of reference evapotranspiration in the Bolivian highlands (Altiplano)," Agric. For. Meteorol., vol. 125, no. 1-2, pp. 67-82, Sep. 2004.

[6] M. Gocic and S. Trajkovic, "Service-oriented approach for modeling and estimating reference evapotranspiration," Comput. Electron. Agric., vol. 79, no. 2, pp. 153-158, Nov. 2011.

[7] W. J. Shuttleworth, "Evaporation Models in Hydrology," in Land Surface Evaporation, New York, NY: Springer New York, 1991, pp. 93-120.

[8] P. Gavilán and F. Castillo-Llanque, "Estimating reference evapotranspiration with atmometers in a semiarid environment," Agric. Water Manag., vol. 96, no. 3, pp. 465-472, 2009.

[9] D. Kool, N. Agam, N. Lazarovitch, J. L. Heitman, T. J. Sauer, and A. Ben-Gal, "A review of approaches for evapotranspiration partitioning," Agric. For. Meteorol., vol. 184, pp. 56-70, Jan. 2014.

[10] P. Martí, P. González-Altozano, R. López-Urrea, L. A. Mancha, and J. Shiri, "Modeling reference evapotranspiration with calculated targets. Assessment and implications," Agric. Water Manag., vol. 149, pp. 81-90, Feb. 2015.

[11] R. G. Allen, L. S. Pereira, D. Raes, M. Smith, and a B. W, "Crop evapotranspiration - Guidelines for computing crop water requirements - FAO Irrigation and drainage paper 56," Irrig. Drain., pp. 1-15, 1998.

[12] R. Ding, S. Kang, Y. Zhang, X. Hao, L. Tong, and T. Du, "Partitioning evapotranspiration into soil evaporation and transpiration using a modified dual crop coefficient model in irrigated maize field with ground-mulching," Agric. Water Manag., vol. 127, pp. 85-96, Sep. 2013.

[13] Y. Li, R. Horton, T. Ren, and C. Chen, "Prediction of annual reference evapotranspiration using climatic data," Agric. Water Manag., vol. 97, no. 2, pp. 300-308, Feb. 2010.

[14] M. R. Hamdi, "Developing Reference Crop Evapotranspiration Time Series Simulation Model using Class Pan A case study for the Jordan Valley," Jordan J. Earth Environ. Sci., vol. 1, no. 1, pp. 33-44, 2008.

[15] S. Kim and H. S. Kim, "Neural networks and genetic algorithm approach for nonlinear evaporation and evapotranspiration modeling," J. Hydrol., vol. 351, no. 3-4, pp. 299-317, Apr. 2008.

[16] G. Landeras, A. Ortiz-Barredo, and J. J. López, "Comparison of artificial neural network models and empirical and semi-empirical equations for daily reference evapotranspiration estimation in the Basque Country (Northern Spain)," Agric. Water Manag., vol. 95, no. 5, pp. 553-565, May 2008.

[17] A. F. Torres, W. R. Walker, and M. McKee, "Forecasting daily potential evapotranspiration using machine learning and limited climatic data," Agric. Water Manag., 2011.

[18] M. Gocic, D. Petković, S. Shamshirband, and A. Kamsin, "Comparative analysis of reference evapotranspiration equations modelling by extreme learning machine," Comput. Electron. Agric., vol. 127, pp. 56-63, Sep. 2016.

[19] S. S. Abdullah, M. A. Malek, N. S. Abdullah, O. Kisi, and K. S. Yap, "Extreme Learning Machines: A new approach for prediction of reference evapotranspiration," J. Hydrol., vol. 527, pp. 184-195, Aug. 2015.

[20] X. Guo, X. Sun, and J. Ma, "Estimating reference crop evapotranspiration using HGA-LSSVM," in 2010 Sixth International Conference on Natural Computation, 2010, pp. 1654-1658.

[21] R. Ahmad, S. F. M. Samsuri, and M. Z. Zakaria, "Evapotranspiration prediction using system identification and genetic algorithm," in Proceedings of the 2nd IASTED Asian Conference on Modelling, Identification, and Control, AsiaMIC 2012, 2012.

[22] S. F. M. Samsuri, R. Ahmad, and M. Z. Zakaria, "Reference Evapotranspiration Estimation in Tropical Region using Penman-Monteith Equation and Evolutionary Computation," in 2nd International Conference on Smart Sensors and Applications (ICSSA2018), 2018.

[23] M. Gocic and S. Trajkovic, "Software for estimating reference evapotranspiration using limited weather data," Comput. Electron. Agric., vol. 71, no. 2, pp. 158-162, May 2010.

[24] R. G. Allen, M. Smith, A. Perrier, and L. S. Pereira, "An Update for the Definition of Reference Evapotranspiration," ICID Bull., 1994.

[25] R. G. Allen, L. S. Pereira, D. Raes, and M. Smith, FAO Irrigation and Drainage Paper No. 56: Crop Evapotranspiration. 1998.

[26] R. Ahmad, H. Jamaluddin, and M. A. Hussain, "Application of memetic algorithm in modelling discrete-time multivariable dynamics systems," Mech. Syst. Signal Process., vol. 22, no. 7, pp. 1595-1609, 2008.

[27] S. A. Billings and H. L. Wei, "An adaptive orthogonal search algorithm for model subset selection and nonlinear system identification,” Int. J. Control, vol. 81, no. 5, pp. 714-724, May 2008.

[28] F. D. Kanellos, G. J. Tsekouras, and N. D. Hatziargyriou, "Wind Parks equivalent ARX models for the simulation of power systems with large wind power penetration, using system-identification theory," Electr. Power Syst. Res., vol. 81, no. 2, pp. 707-715, Feb. 2011.

[29] M. Z. Zakaria, H. Jamaluddin, R. Ahmad, and S. M. Loghmanian, "Comparison between multi-objective and single-objective optimization for the modeling of dynamic systems," Proc. Inst. Mech. Eng. Part I J. Syst. Control Eng., vol. 226, no. 7, pp. 994-1005, Aug. 2012. 
[30] L. Ljung, System Identification: Theory for User. 1999.

[31] C. Zhang and R. R. Bitmead, "MIMO equalization with state-space channel models," IEEE Trans. Signal Process., vol. 56, no. 10 II, pp. 5222-5231, 2008.

[32] J. Ding, F. Ding, and S. Zhang, "Parameter identification of multi-input, single-output systems based on FIR models and least squares principle," Appl. Math. Comput., vol. 197, no. 1, pp. 297-305, Mar. 2008.

[33] J. H. Holland, "Adaptation in Natural and Artificial Systems," Ann Arbor MI Univ. Michigan Press, 1975.

[34] R. Ahmad, H. Jamaluddin, and M. A. Hussain, "Model structure selection for a discrete-time non-linear system using genetic algorithm," no. April 2003, pp. 1-14, 2004.

[35] R. Storn and K. Price, "Differential Evolution - A Simple and Efficient Heuristic for Global Optimization over Continuous Spaces," J. Glob. Optim., 1997.

[36] N. J. D. Nagelkerke, “A note on a general definition of the coefficient of determination,” Biometrika. 1991. 